\title{
Physical and Mechanical Properties and Enthalpy Relaxation Behavior of Polyphenylenesulfidesulfone (PPSS)
}

\author{
Hiroshi Tamada, Shigeru OKita, and Kazuhiko Kobayashi* \\ Toray Industries, Inc., Plastics Research Laboratories, \\ 9-1, Oe-cho, Minato-ku, Nagoya 455, Japan
}

(Received June 3, 1992)

\begin{abstract}
Physical and mechanical properties of polyphenylenesulfidesulfone (PPSS) were measured and compared with those of other high performance sulfur containing amorphous polymers such as polyethersulfone (PES) and polysulfone (PSF). PPSS showed poorer toughness than PES and PSF, and the enthalpy relaxation behavior of PPSS was investigated using DSC in order to understand the brittle nature of PPSS. The rate of enthalpy relaxation of PPSS was found to be very high and the fast relaxation is probably responsible for the brittle nature of PPSS. Dynamic mechanical spectra of PPSS were also measured to supplement the understanding of the relaxation behavior.
\end{abstract}

KEY WORDS Polyphenylenesulfidesulfone / Polyethersulfone / Polysulfone

/ Enthalpy Relaxation / $\beta$ Relaxation /

Sulfur containing amorphous aromatic polymers with high glass transition temperature have been attracting much attention because of their high modulus, excellent thermal resistance, chemical resistance, dimensional stability, flame resistance, etc. The structure of the constitutional unit of these amorphous polymers consists of phenylene groups connected by sulfone and other divalent group(s) such as ether, sulfide and alkylidene, and aromatic nucleophilic substitution reactions are commonly used for the polymerization. ${ }^{1 \mathrm{a}, \mathrm{b}}$ Of these polymers, polyethersulfone (PES) and polysulfone (PSF) have already been commercialized, and recently an another amorphous polymer, polyphenylenesulfidesulfone (PPSS) has been introduced by Phillips Petroleum-Toray Inc. PPSS is produced by almost the same method as the polymerization of polyphenylenesulfide (PPS); $4,4^{\prime}$-dichlorodiphenyl sulfone is condensed with $\mathrm{Na}_{2} \mathrm{~S}$ in $\mathrm{N}$-methylpyrrolidone (NMP).
The sulfide anion displaces the chlorine atom by aromatic nucleophilic substitution reaction to form $\mathrm{C}-\mathrm{S}$ bond. ${ }^{2}$

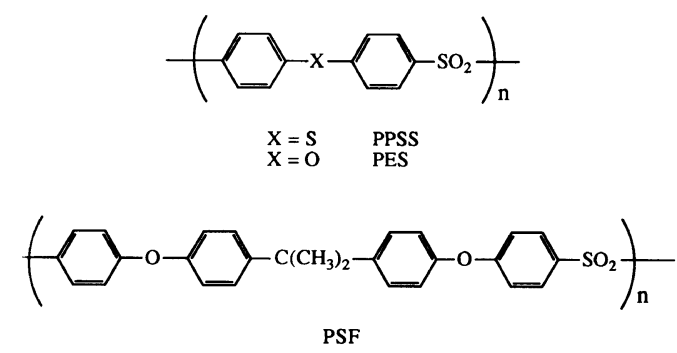

The structural difference between PPSS and PSF, PES is that sulfide (-S-) linkage is incorporated instead of isopropylidene $\left(-\mathrm{CMe}_{2}-\right)$ linkage or ether (-O-) linkage, and it is intriguing to investigate the effects of the chemical structure on the physical and mechanical properties of these amorphous polymers. Therefore, we performed thorough measurements of physical and mechanical properties of PPSS using injection molded

* To whom correspondence should be addressed. 
specimens and compared with those of PES and PSF. One of the characteristic properties of amorphous polymers is excellent toughness which is realized as high value of impact strength or elongation at rupture, and therefore, we paid much more attention to the toughness of PPSS than other properties. Since amorphous polymers are used below the glass transition temperature, they do not undergo embrittlement caused by crystallization. However, enthalpy relaxation occurs below glass transition temperature and relaxation can cause serious embrittlement. This phenomenon is observed for amorphous polymers such as polystyrene, ${ }^{3 \mathrm{a}, \mathrm{b}}$ polycarbonate $(\mathrm{PC}),{ }^{4}$ and PSF. ${ }^{5}$ Recently a conventional method for the evaluation of enthalpy relaxation by using DSC has been developed and rates of the enthalpy relaxation of aromatic polymers have been reported. ${ }^{5,6)}$ We applied this method for evaluating the enthalpy relaxation of PPSS. Dynamic mechanical spectra of PPSS were also measured as supplementary data for understanding the enthalpy relaxation behavior.

\section{EXPERIMENTAL}

\section{Materials}

PES and PSF are commercially available. PPSS samples with different melt viscosities were kindly offered by Phillips PetroleumToray Inc. The trademarks and manufactures of these polymers are listed below.

$$
\begin{array}{rcc}
\text { PES : } & \text { Victrex }{ }^{\circledR} \text { PES 200P } & \text { ICI } \\
\text { PSF : } & \text { Udel }^{\circledR} \text { P-1700 } & \text { Amoco } \\
\text { PPSS : } & (\text { MFR }=25) & \text { Phillips } \\
& (M F R=59) & \text { Petroleum-Toray Inc. }
\end{array}
$$

Melt flow rare (MFR) was measured at $343^{\circ} \mathrm{C}$.

\section{Preparation of Specimens}

The specimens for the measurements of tensile strength, Izod impact strength and flexural modulus were prepared by injection molding using Sumitomo Neomat ${ }^{\circledR}$ at a cylinder temperature of $315-345^{\circ} \mathrm{C}$ and a mold temperature of $150^{\circ} \mathrm{C}$.

\section{Measurement}

Tensile Strength. A Shimadzu Autograph AG-2000C was used for the measurements. The measurement were performed according to ASTM D 638 using injection molded specimens with thickness of $1 / 8$ inch.

Flexural Modulus. A TOYO Boldwin Tensilon UTM-4-200 was used for the measurements. The measurements were performed according to ASTM D 790 using injection molded specimens with thickness of $1 / 4$ inch.

Izod Impact Strength. An Ueshima UF IMPACT TESTER was used for the measurements. The measurements were performed according to ASTM D 256 using injection molded specimens with thickness of $1 / 8$ inch.

Heat Deflection Temperature (HDT). A TOYO SEIKI Heat Distortion Tester No. 533 was used for the measurements. The measurements were performed according to ASTM D 648 using injection molded specimens with thickness of $1 / 4$ inch.

Dynamic Mechanical Spectrum. A TOYO Boldwin Rheovibron Viscoelastometer Rheo $2000 / 3000$ was used for the measurements at a heating rate of $2^{\circ} \mathrm{C} \mathrm{min}-1$ and a frequency of $110 \mathrm{~Hz}$. The measurements were performed using press molded specimens with thikness of $0.3 \mathrm{~mm}$.

Enthalpy Relaxation Behavior. Enthalpy relaxation was measured according to a literature procedure. ${ }^{5,6 \mathrm{a}, \mathrm{b}}$ A Perkin-Elmer DSC-7 was used and the measurements were performed in an atmosphere of $\mathrm{N}_{2}$ with a heating rate of $10^{\circ} \mathrm{C} \mathrm{min}{ }^{-1}$. All the samples were circle shaped thin film with a weight of $15 \pm 1 \mathrm{mg}$.

\section{RESULTS AND DISCUSSION}

Physical and mechanical properties of injection molded specimens of PES, PSF, and PPSS were summarized in Table I. Table I shows that density, water absorption and 
Table I. Physical and mechanical properties of PPSS, PES, and PSF

\begin{tabular}{|c|c|c|c|}
\hline & $\begin{array}{c}\text { PPSS } \\
(\mathrm{MFR}=25)\end{array}$ & $\begin{array}{c}\text { PES } \\
\text { Victrex }{ }^{\circledR} \text { PES 200P }\end{array}$ & $\begin{array}{c}\text { PSF } \\
\text { Udel }^{\circledR} \text { P-1700 }\end{array}$ \\
\hline $\mathrm{S}$ content $($ calcd $) / \%$ & 25.8 & 13.8 & 7.2 \\
\hline Density $/ \mathrm{g} \mathrm{cm}^{-3}$ & 1.40 & 1.37 & 1.24 \\
\hline $\begin{array}{l}T_{\mathrm{g}}^{\mathrm{a}} /{ }^{\circ} \mathrm{C} \\
\text { Refractive index }\end{array}$ & $\begin{array}{l}260 \\
1.71\end{array}$ & $\begin{array}{l}223 \\
1.65\end{array}$ & $\begin{array}{r}187 \\
1.63\end{array}$ \\
\hline $\begin{array}{l}\text { Water absorption } / \% \\
24 \mathrm{~h} \\
\text { equilibrium }\end{array}$ & $\begin{array}{l}0.61 \\
1.28\end{array}$ & $\begin{array}{l}0.62 \\
1.24\end{array}$ & $\begin{array}{l}0.30 \\
0.47\end{array}$ \\
\hline $\begin{array}{l}\text { Tensile strength } / \mathrm{MPa} \\
\text { Elongation at break } / \%\end{array}$ & $\begin{array}{c}99 \\
9.2\end{array}$ & $\begin{array}{l}86 \\
17\end{array}$ & $\begin{array}{l}74 \\
80\end{array}$ \\
\hline $\begin{array}{l}\text { Flexural strength/MPa } \\
\text { Flexural modulus/MPa }\end{array}$ & $\begin{array}{r}145 \\
3030\end{array}$ & $\begin{array}{r}130 \\
2810\end{array}$ & $\begin{array}{r}114 \\
2700\end{array}$ \\
\hline $\begin{array}{l}\text { Izod Impact strength } \\
\text { with mold notch } / \mathrm{J} \mathrm{m}^{-1} \\
\text { without notch } / \mathrm{k} \mathrm{J} \mathrm{m}^{-2}\end{array}$ & $\begin{array}{r}25 \\
109\end{array}$ & $\begin{array}{l}33 \\
\text { Not break }\end{array}$ & $\begin{array}{l}27 \\
\text { Not break }\end{array}$ \\
\hline $\begin{array}{l}\mathrm{HDT}^{\mathrm{b}} \\
\text { load } 1.82 \mathrm{MPa} /{ }^{\circ} \mathrm{C}\end{array}$ & 185 & 175 & 207 \\
\hline
\end{tabular}

a On-set temperature.

${ }^{b}$ Heat Deflection Temperature.

refractive index of PPSS are higher than those of PES and PSF. Density, refractive index and water absorption increased in the order of PSF $<$ PES $<$ PPSS. The mechanical properties showed a similar tendency. Under our experimental conditions, both the tensile strength and flexural strength increased in the order of PSF $<$ PES $<$ PPSS, while the elongation at rupture decreased in the order of PSF $>$ PES $>$ PPSS. Since the elongation at rupture of the injection molded specimens of PPSS was quite low compared with PES and PSF, we investigated the effects of molding condition on the tensile properties of PPSS. PPSS was press molded into sheets under various conditions and specimens for tensile test were cut from the press molded sheets. The molding conditions and results of the tensile test performed at $25^{\circ} \mathrm{C}$ are summarized in Table II. From the data shown in Table II, it is clear that quenched samples show relatively high values of elongation at rupture $(30-66 \%)$, while slowly cooled samples showed values of only $18-20 \%$. We also investigated the effect of annealing performed at a temperature below $T_{\mathrm{g}}$ on elongation at rupture. In Figure 1, the values of the elongation at rupture of the PPSS samples annealed at $120^{\circ} \mathrm{C}$ are plotted against the annealing time. The elongation at rupture rapidly decreased with annealing time, from over $40 \%$ to $10 \%$ within $1 \mathrm{~h}$. Based on these results, it is most likely that the poor toughness of the injection molded specimens of PPSS (Table I) is caused by annealing during cooling in the mold. As already mentioned, the enthalpy relaxation has been observed for other polymers such as polystyrene, ${ }^{3 \mathbf{a}, \mathbf{b}}$ polycarbonate, ${ }^{4}$ and $\mathrm{PSF}^{5}$ and it is believed that polymer chains frozen into metastable configuration can relax on annealing performed at a temperature velow $T_{\mathrm{g}}$ so that the chains can pack together more closely. This phenomenon is also called free volume relaxation when the monitored quantity is the free volume. It has already been reported that the enthalpy relaxation or the free volume relaxation causes embrittlement, ${ }^{3-6}$ and therefore, we assumed that the rate of the enthalpy relaxation of PPSS might 
Table II. Effects of molding conditions on tensile properties of PPSS

\begin{tabular}{|c|c|c|c|c|c|c|c|c|}
\hline \multirow{5}{*}{ Entry } & \multirow{5}{*}{$\begin{array}{c}\text { MFR } \\
\left(343^{\circ} \mathrm{C}\right)\end{array}$} & \multicolumn{3}{|c|}{ Press molding conditions } & \multicolumn{4}{|c|}{ Tensile test } \\
\hline & & \multirow{2}{*}{ Mold temp. } & \multirow{4}{*}{ Retention time } & \multirow{4}{*}{$\begin{array}{l}\text { Cooling } \\
\text { method }^{\mathrm{a}}\end{array}$} & \multicolumn{2}{|c|}{ Yield } & \multicolumn{2}{|c|}{ Rupture } \\
\hline & & & & & Stress & Elongation & Stress & Elongation \\
\hline & & ${ }^{\circ} \mathrm{C}$ & & & & & & \\
\hline & & & & & $\mathrm{MPa}$ & $\%$ & $\mathrm{MPa}$ & $\%$ \\
\hline 1 & 25 & 310 & 30 & Q & 87 & 9.0 & 61 & 30.3 \\
\hline 2 & 25 & 310 & 60 & Q & 86 & 8.5 & 62 & 42.8 \\
\hline 3 & 25 & 320 & 15 & $\mathrm{Q}$ & 89 & 9.3 & 62 & 34.5 \\
\hline 4 & 25 & 320 & 30 & $\mathrm{Q}$ & 84 & 10.0 & 60 & 53.5 \\
\hline 5 & 25 & 320 & 30 & R.T. & 94 & 8.5 & 63 & 18.5 \\
\hline 6 & 25 & 320 & 180 & Q & 88 & 9.0 & 61 & 36.3 \\
\hline 7 & 25 & 320 & 420 & $\mathrm{Q}$ & 90 & 9.0 & 62 & 30.5 \\
\hline 8 & 25 & 340 & 60 & Q & 86 & 8.7 & 63 & 66.3 \\
\hline 9 & 25 & 340 & 60 & R.T. & 95 & 9.0 & 63 & 20.2 \\
\hline 10 & 59 & 310 & 60 & Q & 82 & 7.5 & 58 & 33.0 \\
\hline 11 & 59 & 320 & 30 & $\mathrm{Q}$ & 85 & 8.5 & 59 & 31.1 \\
\hline
\end{tabular}

${ }^{\text {a }} \mathrm{Q}$, quenched at $0^{\circ} \mathrm{C}$ (ice water); R.T., cooled at room temperature.

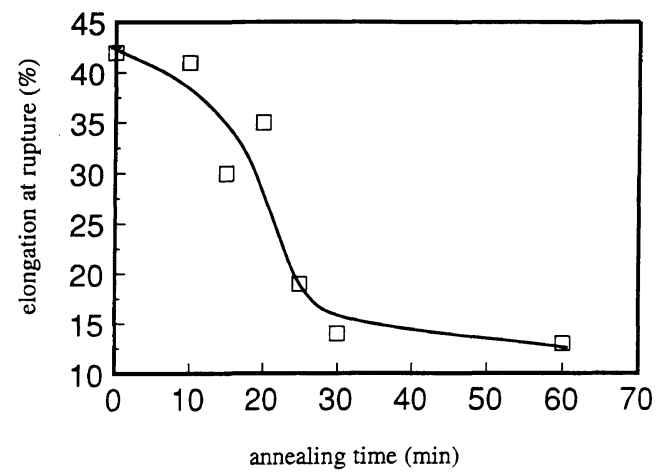

Figure 1. Effects of annealing time on elongation at rupture of PPSS specimen (annealing temp, $120^{\circ} \mathrm{C}$; tensile test temp, $25^{\circ} \mathrm{C}$ ).

be very high and the enthalpy relaxation might have occurred even during the cooling in the mold.

The enthalpy relaxation was investigated according to a literature procedure using DSC. ${ }^{3 \mathbf{a}, 5,6 \mathbf{a}, \mathbf{b}}$ Figures 2 and 3 show representative DSC curves of quenched PPSS samples (in the metastable glass state) and that of annealed PPSS sample (in the relaxed glass state), respectively. In both DSC curves shown in
Figures 2 and 3, two transitions are observed at $206^{\circ} \mathrm{C}$ and $225^{\circ} \mathrm{C}$ (on-set temperatures). The transition observed at $206^{\circ} \mathrm{C}$ is apparantly referred to $T_{\mathrm{g}}$ of PPSS, but the reason for the appearance of the small transition observed at $225^{\circ} \mathrm{C}$ is not clear. Until the present, the small transition at $225^{\circ} \mathrm{C}$ is most probably referred to $T_{\mathrm{g}}$ of PES segment which could be incorporated into the PPSS polymer chain during polymerization because it is well known that 4,4'-dichlorodiphenyl sulfone is hydrolyzed under basic conditions to form 4-chloro4'-hydroxydiphenyl sulfone which yields PES under basic conditions. ${ }^{7 \mathrm{a}-\mathrm{c}}$

Excess enthalpy of a quenched sample $\left(\Delta H_{\mathrm{o}}\right)$ is defined as eq 1 ,

$$
\Delta H_{0}=\Delta C_{\mathrm{p}}\left(T_{\mathrm{g}}-T_{\mathrm{a}}\right)
$$

where $T_{\mathrm{a}}$ is a quenching temperature, and $\Delta C_{\mathrm{p}}$ is difference between the heat capacity of the liquid state and that of the quenched glass state at $T_{\mathrm{g}}$. Both the heat capacity of the liquid state at $T_{\mathrm{g}}$ and that of the quenched glass state at $T_{\mathrm{g}}$ are obtained by interpolating respectively the $C_{\mathrm{p}}$ line at the glass state and at the liquid 


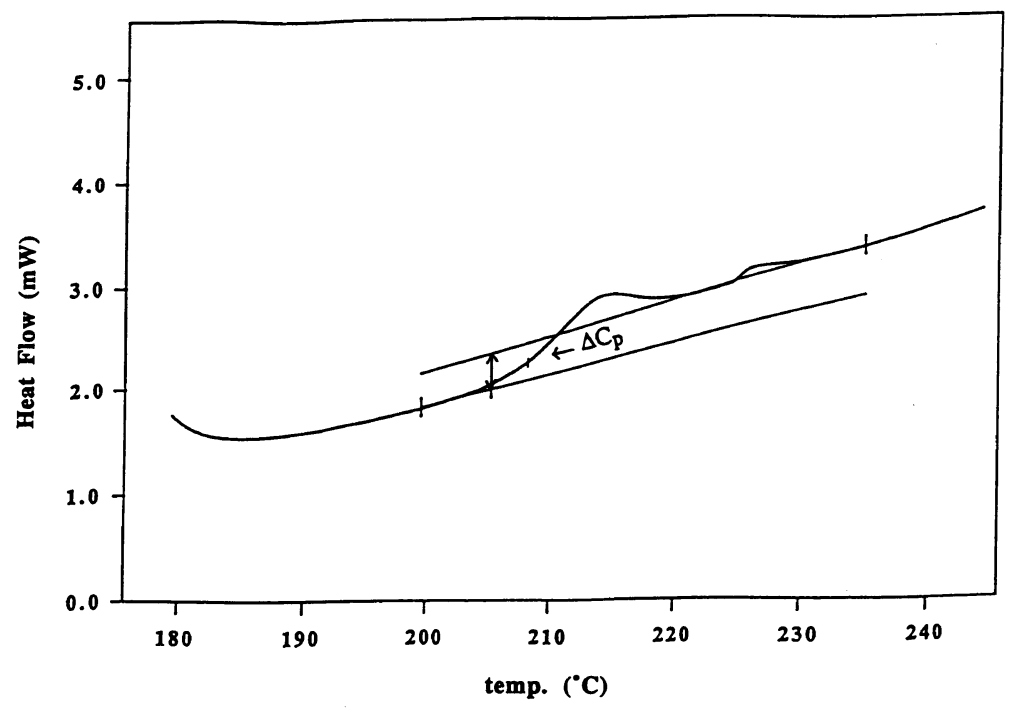

Figure 2. DSC profile of quenched PPSS film: on-set temp, $206^{\circ} \mathrm{C}$; middle of the heat capacity, $208^{\circ} \mathrm{C}$; $\Delta C_{\mathrm{p}}, 0.145 \mathrm{Jg}^{-1} \mathrm{deg}$.

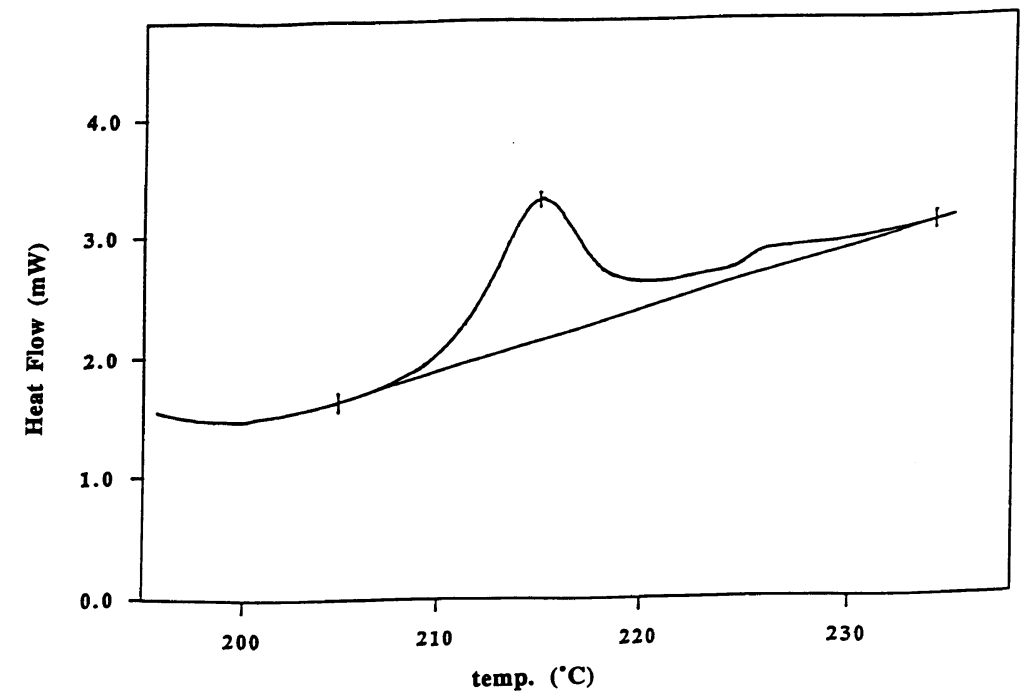

Figure 3. DSC profile of PPSS film annealed at $191^{\circ} \mathrm{C}$ for $90 \mathrm{~min}$ : peak temp, $215^{\circ} \mathrm{C} ; \Delta H, 3.34 \mathrm{~J} \mathrm{~g}^{-1}$.

state to the glass transition temperatures as shown in Figure 2. We used the on-set temperature as $T_{\mathrm{g}}$, and PPSS showed an on-set temperature at $206^{\circ} \mathrm{C}$. Thus, $\Delta C_{\mathrm{p}}=0.145 \mathrm{~J} \mathrm{~g}^{-1}$ deg was obtained for PPSS. Similarly, $T_{\mathrm{g}}$ and $\Delta C_{\mathrm{p}}$ of PES were $223^{\circ} \mathrm{C}$ and $0.174 \mathrm{~J} \mathrm{~g}^{-1} \mathrm{deg}$ (lit. ${ }^{5} T_{\mathrm{g}}=223^{\circ} \mathrm{C}, \Delta C_{\mathrm{p}}=0.222 \mathrm{Jg} \mathrm{g}^{-1} \mathrm{deg}$ ).
The enthalpy which is relaxed during annealing $\left(\Delta H_{\mathrm{d}}\right)$ is obtained by eq 2 ,

$$
\Delta H_{\mathrm{d}}=\int_{T_{\mathrm{t}}}^{T_{\mathrm{f}}} C_{\mathrm{pa}}(T) \mathrm{d} T-\int_{T_{\mathrm{a}}}^{T_{\mathrm{f}}} C_{\mathrm{po}}(T) \mathrm{d} T
$$

where $C_{\mathrm{pa}}(T)$ and $C_{\mathrm{po}}(T)$ are the heat capacity of an annealed sample and quenched sample, 
respectively. $T_{\mathrm{a}}$ is a quenching temperature and $T_{\mathrm{f}}$ is a temperature above $T_{\mathrm{g}}$ at which transition is complete. Experimentarily, $\Delta H_{\mathrm{d}}$ is obtained as the difference of the transition area between an annealed sample and a quenched sample. Then, the total excess enthalpy of an annealed sample $\left(\Delta H_{t}\right)$ is defined as eq 3 .

$$
\Delta H_{\mathrm{t}}=\Delta H_{\mathrm{o}}-\Delta H_{\mathrm{d}}
$$

Using the above equations, enthalpy relaxation behavior of PPSS and PES was investigated. In the case of PPSS, samples were heated to $236^{\circ} \mathrm{C}$ at a heating rate of $20^{\circ} \mathrm{Cmin}^{-1}$, maintained at this temperature for $5 \mathrm{~min}$ to erase any thermal history of the samples, cooled to an annealing temperature with a cooling rate of $10^{\circ} \mathrm{C} \mathrm{min}{ }^{-1}$, annealed for a certain time of periode, and finally heated to $236^{\circ} \mathrm{C}$ at a heating rate of $10^{\circ} \mathrm{C} \mathrm{min}^{-1}$. A similar program was used for PES. To calculate the excess

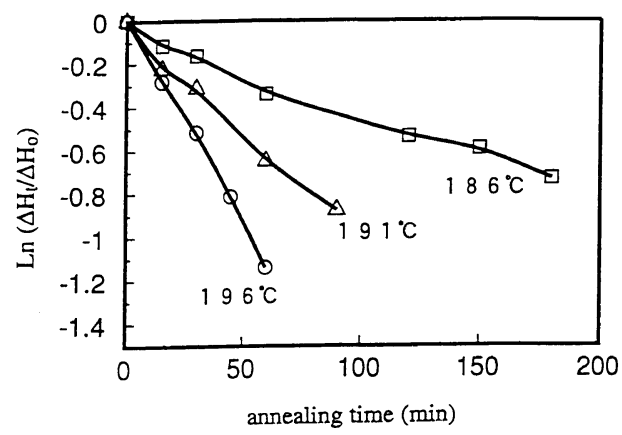

Figure 4. Enthalpy relaxation behavior of PPSS at 186, 191 , and $196^{\circ} \mathrm{C}$.

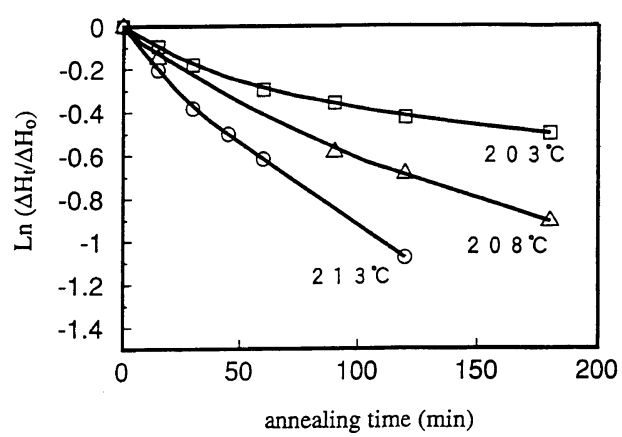

Figure 5. Enthalpy relaxation behavior of PES at 203, 208 , and $213^{\circ} \mathrm{C}$. enthalpy based on eq 2 and 3 , we used $T_{\mathrm{f}}=234^{\circ} \mathrm{C}$ for PPSS and $T_{\mathrm{f}}=240^{\circ} \mathrm{C}$ for PES.

Excess enthalpy changes of PPSS and PES with annealing time are presented in Figures 4 and 5. In Figures 4 and $5, \ln \left(\Delta H_{\mathrm{t}} / \Delta H_{\mathrm{o}}\right)$ is used as ordinate, which represents the extent of the relaxation of the excess enthalpy. In the case of PPSS, annealing was performed at 186, 191, and $196^{\circ} \mathrm{C}$, which correspond to $\left(T_{\mathrm{g}}-20\right)$, $\left(T_{\mathrm{g}}-15\right)$, and $\left(T_{\mathrm{g}}-10\right)^{\circ} \mathrm{C}$, respectively. Similarly, in the case of PES, annealing was performed at 203,208 , and $213^{\circ} \mathrm{C}$. From Figures 4 and 5 , the relaxation time at $\Delta H_{\mathrm{t}} / \Delta H_{\mathrm{o}}=0.5$ $\left(\tau_{1 / 2}\right.$ value $)$ is obtained for each polymer, and the relationship between $\tau_{1 / 2}$ and $\left(T_{\mathrm{g}}-T_{\mathrm{a}}\right)$ is plotted in Figure 6. As shown in Figure 6, the $\tau_{1 / 2}$ value of PPSS is lower than that of PES over a wide range of $\left(T_{\mathrm{g}}-T_{\mathrm{a}}\right)$ and this means that PPSS relaxes its excess enthalpy faster than PES. It is most likely that the injection molded sample of PPSS relaxed its excess enthalpy during cooling in the mold and consequently exhibited poor toughness. According to the literature, ${ }^{5}$ the enthalpy relaxation of PSF is faster than PES over a wide range of $\left(T_{\mathrm{g}}-T_{\mathrm{a}}\right)$. However, compared at a specific temperature, at $150^{\circ} \mathrm{C}$ for example, $\tau_{1 / 2}$ of PSF is larger than that of PES. This means that the relaxation rates of the polymers at our mold temperature $\left(150^{\circ} \mathrm{C}\right)$ increase in the order of PPSS $<\mathrm{PES}<\mathrm{PSF}$, and this order corresponds to the order of

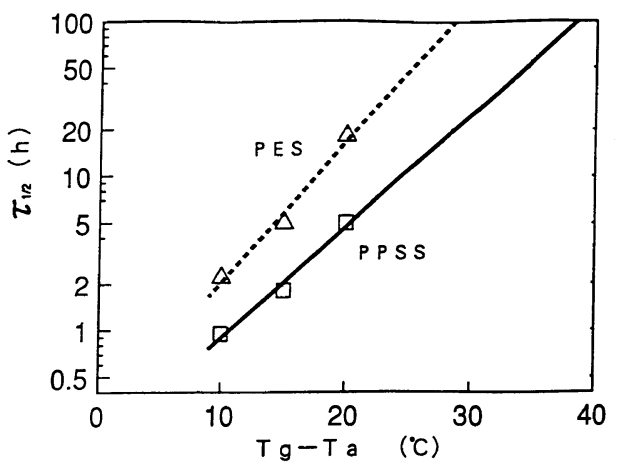

Figure 6. Half value period of enthalpy relaxation $\tau_{1 / 2}$ versus $\left(T_{\mathrm{g}}-T_{\mathrm{a}}\right)$. 


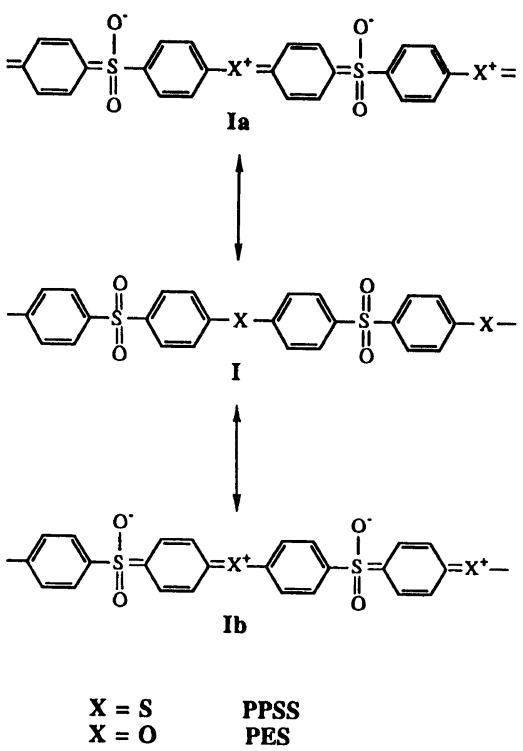

Scheme 1. Resonance structures of PPSS and PES.

toughness of the injection molding specimens.

Excess enthalpy is believed to relax through rotation of the polymer chain ${ }^{5,6 a, 8}$ and from the above results we believe that the rotation along the polymer chain of PPSS is easier than those of PES and PSF. As presented in Scheme 1, PES and PPSS have the same type of resonance structures containing double bond character $\mathrm{Ia}$ and $\mathrm{Ib}$. However, $\mathrm{S}=\mathrm{C}$ bond is much less stable than $\mathrm{C}=\mathrm{O}$ bond,,$^{9 \mathrm{a}, \mathrm{b}}$ and therefore, the contribution of the resonance structure $\mathrm{Ib}$ in PPSS is much less than in PES. Thus, the contribution of the resonance structure with double bond character is scarce in PPSS and the rotation of the polymer chain of PPSS is less hindered. In the case of PSF, a direct comparison with PPSS is difficult because of the difference of their chemical structures. However, it seems likely that the rotation along the polymer chain of PSF is more restricted by the steric hindrance of isopropylidenic group and the relaxation is slower than PES under our molding condition.

The relaxation behavior of PPSS was also analyzed by dynamic mechanical spectra. The

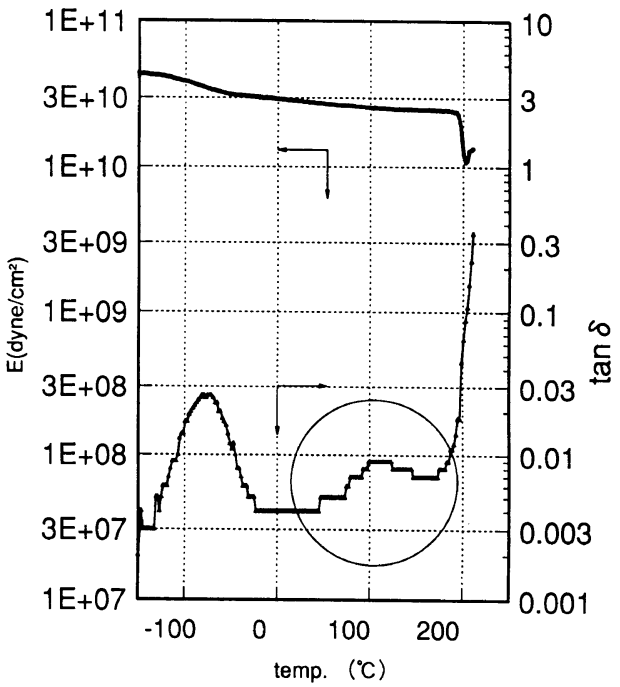

Figure 7. Plot of dynamic storage modulus and $\tan \delta$ versus temperature for quenched PPSS film (frequency, $110 \mathrm{~Hz})$.

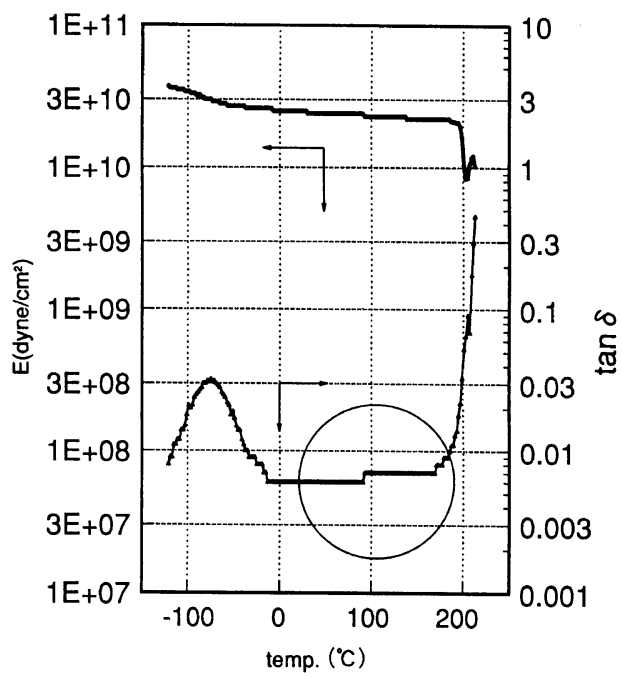

Figure 8. Plot of dynamic storage modulus and $\tan \delta$ versus temperature for gradually cooled PPSS film (gradually cooled to room temperature inside the press mold after pressed at $320^{\circ} \mathrm{C}$; frequency, $110 \mathrm{~Hz}$ ).

dynamic mechanical spectra of the quenched PPSS sample and annealed PPSS sample are presented in Figures 7 and 8. As expected, the quenched sample showed a broad peak around $120^{\circ} \mathrm{C}$ which is referred to $\beta$ peak, while the 
annealed PPSS sample did not show this kind of peak. It has been reported that $\beta$ peak is associated with relaxation involving long-range cooperative motion. ${ }^{10}$ This process is supposed to occur in defect regions which have been frozen by rapid quenching from the melt. Thus, the dynamic mechanical behavior of PPSS is in good accordance with the enthalpy relaxation behavior analyzed by DSC. We believe that the poor toughness of PPSS as shown in Tables I and II is ascribed to facile enthalpy relaxation, and therefore, the incorporation of a bulky unit into the polymer chain of PPSS in order to hinder the rotation along the polymer chain may improve the toughness of PPSS.

\section{REFERENCES}

1. a) F. Parodi, in "Comprehensive Polymer Science," Vol. 5, G. Allen and J. C. Bevington, Ed., Pergamon Press, Oxford, 1989, p 561.

b) "Encyclopedia of Polymrer Science and Engineer- ing," 2nd ed, Vol. 13, Wiley-Interscience, 1988, p 197.

2. D. R. Fahey and C. E. Ash, Macromolecules, 24, 4242 (1991).

3. a) H. Yoshida and Y. Kobayashi, Polym. Commun., 24, 336 (1983).

b) R.-J. Roe and G. M. Millman, Polym. Eng. Sci., 23(6), 318 (1983).

4. M. Washer, Polymer, 26, 1546 (1985).

5. H. Yoshida, Netsu Sokutei, 15(2), 65 (1988).

6. a) H. Yoshida, Netsu Sokutei, 13(4), 191 (1986).

b) T. Hatakeyama, H. Yoshida, S. Hirose, and H. Hatakeyama, Thermochim. Acta, 163, 175 (1990).

7. a) A. B. Newton and J. B. Rose, Polymer, 13, 465 (1972).

b) T. E. Attwood, D. A. Barr, G. G. Feasey, V. J. Leslie, A. B. Newton, and J. B. Rose, Polymer, 18, 354 (1977).

c) T. E. Attowood, D. A. Barr, T. King, A. B. Newton, and J. B. Rose, Polymer, 18, 359 (1977).

8. H. Yoshida, J. Macromol. Sci., B21, 565 (1982).

9. a) J. D. Roberts and M. C. Caseiro, "Basic Principles of Organic Chemistry,” W. A. Benjamin, Inc., New York, 1964, p 745.

b) F. Duus in "Comprehensive Organic Chemistry," Vol. 3, D. H. R. Barton and W. D. Ollis, Ed., Pergamon Press, 1979, p 374.

10. J. R. Fried, A. Letton, and W. J. Welsh, Polymer, 31, 1032 (1990). 